\title{
Impingement is not impingement: the case for calling it "Rotator Cuff Disease"
}

\author{
Edward G. McFarland 1 \\ Nicola Maffulli2 \\ Angelo Del Buono 3 \\ George A. C. Murrell 4 \\ Juan Garzon-Muvdi ${ }^{1}$ \\ Steve A. Petersen ${ }^{1}$
}

1 Division of Shoulder Surgery, Department of Orthopaedic Surgery, The Johns Hopkins University, Baltimore MD, USA

2 Department of Physical and Rehabilitation Medicine, University of Salerno School of Medicine and Surgery, Salerno, Italy. Centre for Sports and Exercise Medicine, Queen Mary University of London, Barts and The London School of Medicine and Dentistry, Mile End Hospital, London, UK

${ }^{3}$ Department of Orthopaedic and Trauma Surgery, Campus Biomedico University of Rome, Italy

${ }^{4}$ Orthopaedic Research Institute, University of South Wales, The St George Hospital, Sydney, Australia

Corresponding author:

Edward G. McFarland

c/o Elaine P. Henze, BJ, ELS, Medical Editor and Director, Editorial Services, Department of Orthopaedic Surgery, The Johns Hopkins University/Johns Hopkins Bayview Medical Center

4940 Eastern Ave, \#A665, Baltimore, MD 212242780, USA

E-mail: ehenze1@jhmi.edu

\section{Summary}

Historically, many causes have been proposed for rotator cuff conditions. The most prevalent theory is that the rotator cuff tendons, especially the supraspinatus, make contact with the acromion and coracoacromial ligament, resulting in pain and eventual tearing of the tendon. However, more recent evidence suggests that this concept does not explain the changes in rotator cuff tendons with age. The role of acromioplasty and coracoacromial ligament release in the treatment of rotator cuff disease has become questioned. Evidence now suggests that tendinopathy associated with aging may be a predominant factor in the development of rotator cuff degeneration. We propose that the overwhelming evidence favors factors other than "impingement" as the major cause of rotator cuff disease and that a paradigm shift in the way the development of rotator cuff pathology is conceptualized allows for a more comprehensive approach to the care of the patient with rotator cuff disease.

KEY WORDS: acromioplasty, impingement, rotator cuff, shoulder, tendinopathy surgery, treatment.

\section{Introduction}

The cause of rotator cuff conditions has been debated for more than 100 years. Theories include intrinsic tendon degeneration, vascular factors, tension overload, differential stress in layers of the tendon, and impingement syndromes. The latter has become synonymous with all rotator cuff conditions and rotator cuff disease in general. As a result, anterior and lateral shoulder pain is commonly described by many providers as "impingement". However, rotator cuff disease is a condition with protean presentation and multifactorial intrinsic or extrinsic causes, and biologic, biomechanical, anatomical, and clinical information increasingly suggests that the theory of impingement often does not reflect the reality of the pathogenesis of rotator cuff disease. This commentary will make the arguments that: 1) the term "impingement" for the symptoms of rotator cuff abnormalities does not reflect modern knowledge and promulgates a viewpoint that adversely affects the science and the evolution of patient treatment, 2) the pathogenesis of rotator cuff disorders results from a variety of factors and not just "impingement" and that, therefore, the constellation of symptoms attributed to rotator cuff abnormalities should be called "rotator cuff disease."

\section{History of terminology and current findings}

It was only in 1972 that $\mathrm{Dr}$. Charles Neer ${ }^{1}$ fully elucidated the idea that rotator cuff problems resulted from contact or "impingement" of the rotator cuff tendons to the acromion, to the coracoacromial ligament, or to the undersurface of the acromioclavicular joint. His revolutionary idea was that the condition could be successfully treated by partial anterolateral acromioplasty and coracoacromial ligament release as opposed to total acromionectomy. For the last 40 years, the Neer concept of "impingement" has been the overwhelming theory on the cause of rotator cuff disease and the basis for clinical tests for deciphering its symptoms, for describing radiographic or magnetic resonance imaging changes, and for the rationale for non-operative and surgical treatment. Over 
time, the concept of impingement has been altered to include other potential causes of rotator cuff abnormality, such as contact with the superior glenoid contact (arm in flexion) ${ }^{2,3}$, with the posterior and superior labrum (arm in abduction and external rotation) ${ }^{4,5}$, and with the coracoid (arm in flexion and internal rotation) 6 .

Increasingly, rotator cuff disease has been appreciated as a form of the tendinopathy seen in other tendons in the body. It is an overuse tendinopathy that includes a spectrum of clinical features and pathologic characteristics ${ }^{7}$. Despite the frequent use of the term "tendinitis", rotator cuff tendinopathy is characterized histologically by little evidence of inflammation. Instead, histologically, the findings are more typical of a "failed healing response", with a haphazard proliferation of tenocytes, intracellular abnormalities in tenocytes, disruption of collagen fibers, and subsequent increase in non-collagenous matrix ${ }^{8-10}$. Some of these intratendinous changes may be related to the normal ageing process of the tendon and soft tissues ${ }^{11}$, but the exact pathophysiologic mechanism is still unclear. However, heavy physical loading, injury, vibration, infection, smoking, genetic factors, and fluoroquinolone antibiotics can produce such histologic features ${ }^{11}$.

The exact cause of tendinopathy in any tendon remains controversial and may involve a combination of factors intrinsic to the tendon and of extrinsic factors $^{12,13}$. Excessive load, repetitive load, or loads applied from different directions have been implicated in the process of tendinopathy. Other theories include localized hypoxia produced by tensile load ${ }^{14}$, hyperthermic injury as the tendon heats up with exercise ${ }^{15}$, tenocyte apoptosis ${ }^{16}$, and cytokines or proteolytic enzymes released as a result of applied stress ${ }^{17}$. The release of nitrous oxide has also been implicated in the tendinopathy process ${ }^{18}$.

The pain related to rotator cuff disease has been reported to be associated with stimulation of the free nerve endings in the bursa. One report indicated that the stimulation was provided by one or more of the substances mentioned above ${ }^{19}$. A histologic study has shown that the largest number of free nerve endings around the should be in the subacromial bursa, followed by the biceps tendon and the capsule ${ }^{20}$. The rotator cuff tendons have few free nerve fibers, so although the tendons play a role in generating pain, it is most likely through some indirect mechanism whereby some peptides or transmitters initiate a pain response from the pain fibers in the bursa, biceps tendon, or the joint lining 21 .

There are several other concerns with the theory of impingement as a cause of rotator cuff disease. Although rotator cuff tears have been shown to be associated with spurs on the acromion and the shape of the acromion, these two observations have not been proven to be causally related. Morrison and Bigliani22 described three acromial shapes that increased with age and were associated with rotator cuff tears, but this relationship was not causally established in that work. Unfortunately, studies have shown that the ra- diograph to determine the acromial shape does not have high intra- or interobserver reliability ${ }^{23-25}$. The shape of the acromion is also affected by the angle of the radiograph, so subtle changes in the radiological beam can change the perceived shape of the acromion.

The traditional surgical treatment for rotator cuff symptoms has been a partial anterolateral acromioplasty and a release of the coracoacromial ligament. To our knowledge, no clinical study has correlated surgical results with converting the acromion shape to a type 1. One study evaluated acromial shape in patients with preoperative small to medium rotator cuff tears and prospectively randomized the patients to cuff repair with or without acromioplasty ${ }^{26}$. They found that both groups had the same tendon re-tear rate and that the failure had no correlation to acromial shape ${ }^{26}$. The success of rotator cuff surgery has been largely reported to be independent of acromioplasty and coracoacromial ligament release ${ }^{1,27-29}$. Holt and Allibone $^{30}$ found that one of the major functions of the coracoacromial ligament was to serve as a major restraint to superior migration of the humeral head, especially in the presence of large to massive rotator cuff tears. Several studies have reported no difference in clinical results for patients who had rotator cuff surgery with or without acromioplasty and coracoacromial ligament release $\mathrm{e}^{26,31-33}$. In a systematic review, Chahalet al. ${ }^{34}$ reported, at intermediate follow-up, no difference in subjective results for arthroscopic rotator cuff repair with or without partial acromioplasty.

There also is a large disconnect between the presence of a rotator cuff tear and the presence of pain. Some patients with large rotator cuff tears have no pain whatsoever, whereas some with small tears have substantial pain. Numerous clinical studies ${ }^{35-37}$ have shown that an overwhelming percentage of patients who have a failed rotator cuff repair obtain pain relief from surgery despite the fact that one or more rotator cuff tendons may be torn. These studies suggest that rotator cuff tendon healing to bone is not necessary for a good surgical result and that some mechanism other than impingement is responsible for the pain.

Other investigators have questioned the role of acromioplasty in preventing the progression of rotator cuff disease. In a nine-year follow-up of 96 patients who had partial anterolateral acromioplasty, Hyvönen et al. ${ }^{38}$ reported that, in $20 \%$ of their patients, the rotator cuff disease progressed, suggesting other etiologic factors as causative in the disease. Kartus et al. ${ }^{39}$ found that, in a long-term (9 years) follow-up of a cohort of patients with partial anterolateral acromioplasty, more than one third of the patients had rotator cuff disease progression so that the failure rate of the repairs increased over time. They concluded that rotator cuff surgery consisting anterolateral acromioplasty did not prevent progression of the disease.

Rotator cuff disease has been the subject of several extensive analyses. A recent systematic review by Papadonikolakis et al. ${ }^{40}$ examined five commonly held assumptions about rotator cuff disease. They re- 
ported little support in the literature for acromioplasty and its place in the treatment of rotator cuff disease. In a consensus statement on the management of rotator cuff disease, the American Academy of Orthopedic Surgeons suggested that few treatments of rotator cuff disease can be supported by high level of evidence studies ${ }^{41}$. Therefore, it is logical to conclude that rotator cuff disease is the result of a combination of intrinsic tendon factors and extrinsic factors ${ }^{42}$. Intrinsic factors would include the poorly understood process of progressive tendinopathy, the poor blood supply near the insertion of the tendons, and the inability of the tendons to heal intrinsically ${ }^{43}$. Extrinsic factors would include the amount of stress applied to the tendon by tension or muscle activity and also potentially the impingement of the tendons on other structures.

One of the main reasons to desist calling rotator cuff disease "impingement" is that it limits the thinking of practitioners and researchers who address this condition. Rotator cuff disease is a complex disease entity, as are painful tendinopathies in other parts of the body. The framework of "impingement" defies the complexity of the process, and researchers need to be able to study this condition without this restrictive concept. Braman et al. ${ }^{44}$ suggested that the term "impingement" should be replaced with either anterior or posterior "shoulder pain" and that the term "impingement" is too broad and includes too many possible pathomechanical entities.

There are other medical practitioners whose interpretation of this disease influences how orthopaedic surgeons manage patients. For example, radiologists often describe "impingement" of the acromion on the rotator cuff or suggest that the acromial morphology is consistent with "impingement". It is also not uncommon to have radiologists comment in reports on "impingement" of spurs at the acromioclavicular joint on the muscular portion of the supraspinatus muscle. This information confuses patients, and radiologists not infrequently suggest that surgery to remove the spurs is recommended. Physical therapists, too, often express concerns that patients under their treatment have "impingement" when, in reality, they have anterior and lateral shoulder pain from a variety of causes. The causes of anterior and lateral shoulder pain include arthritis, stiffness, biceps tendon tenosynovitis or tears, rotator cuff abnormalities, instability, and superior labrum anterior and posterior tears. In fact, the examination for this constellation of symptoms is inexact, and to conclude that it is "impingement pain" limits one's ability to reach a proper diagnosis and deliver proper treatment to the patient. In our opinion, pain in the anterior and lateral shoulder should be called "anterolateral shoulder pain syndrome" and not "impingement" pain.

Another pervasive theory is that rotator cuff impingement is associated with a protracted scapula, such as is seen with kyphosis of the spine or in some athletes ${ }^{45}$. The theory is that, in athletes, the protracted scapula is accompanied by a relative anterior tilting of the scapula, which has been reported to decrease the subacromial space ${ }^{46}$, causing the rotator cuff to impinge on the acromion ${ }^{47}$. Physical therapy is directed at correcting the protracted scapula. However, if impingement is not impingement, meaning that the pathophysiology is not the rotator cuff hitting the acromion, then it is likely that other mechanisms, and not acromial contract, result in pain in patients with a protracted scapula. The cause-and-effect relationship between a protracted scapula and pain is currently not known. It is entirely possible that the shoulder reacts to pain of any cause by becoming protracted to decrease stress on the tendons or other structures. If rotator cuff disease is not primarily an impingement issue, then this theory and the observations of scapular motion may need to be revised to include other possible mechanisms of the pain.

Similarly, increasing kyphosis, which is seen with increasing age, has been postulated as a cause of rotator cuff disease by creating a protracted scapula. The theory is that the protracted scapula closes down the subacromial space and leads to "impingement pain" 48 . However, causality between the two observations has not been proved, and if rotator cuff disease is primarily a degenerative phenomenon and not the result of impingement, then it is possible that kyphosis has nothing to do with the development of rotator cuff disease and that the two phenomena are purely age-related changes. This change in conceptualizing impingement as the cause of rotator cuff disease would drastically change the approach to patients previously thought to have rotator cuff symptoms from structural kyphosis or from kyphosis associated with poor posture.

\section{Conclusions}

Rotator cuff disease is a multifactorial condition, the origin of which is unclear, but the failed healing response typically seen in other tendinopathies is the end result. The predominant theory of causality in which the rotator cuff wears down after contact with one structure or another has not been proven and does not explain the clinical manifestations of the condition. As a result, we recommend that the spectrum of rotator cuff abnormalities no longer be called "impingement disease" but rather "rotator cuff disease". Similarly, pain in the anterior and lateral shoulder should not be presumed to arise from rotator cuff contact with structures and should no longer be called "impingement pain" but rather "anterolateral shoulder pain". Evidence for continuing to focus on acromial morphology and acromial shape as a major contributor to rotator cuff disease is inadequate. Imaging studies reporting that there is "impingement" should be modified to note contact between structures but should no longer be interpreted as "impingement" because causality cannot be established on a static radiographic study. Lastly, clinical and experimental energy should be directed toward establishing the pathophysiology of rotator cuff disease, its natural history, the source of pain in rotator cuff disease, and 
its effective treatments. The term "rotator cuff disease" will free the scientific community from the restraints of the limitations of the concept of "impingement" and will allow exploration of other causes and treatments.

\section{References}

1. Neer CS, II. Anterior acromioplasty for the chronic impingement syndrome in the shoulder: a preliminary report. J Bone Joint Surg Am 1972; 54(1):41-50.

2. Jia X, Ji JH, Pannirselvam V, Petersen SA, McFarland EG. Does a positive Neer impingement sign reflect rotator cuff contact with the acromion? Clin Orthop Relat Res 2011; 469(3):813-818.

3. Kim TK, McFarland EG. Internal impingement of the shoulder in flexion. Clin Orthop Relat Res 2004; 421:112-119.

4. Davidson PA, Elattrache NS, Jobe CM, Jobe FW. Rotator cuff and posterior-superior glenoid labrum injury associated with increased glenohumeral motion: a new site of impingement. J Shoulder Elbow Surg 1995; 4(5):384-390.

5. McFarland EG, Hsu CY, Neira C, O'Neil O. Internal impingement of the shoulder: a clinical and arthroscopic analysis. J Shoulder Elbow Surg 1999; 8(5):458-460.

6. Gerber C, Terrier F, Ganz R. The role of the coracoid process in the chronic impingement syndrome. J Bone Joint Surg Br 1985; 67(5):703-708.

7. Maffulli N, Longo UG, Maffulli GD, Rabitti C, Khanna A, Denaro V. Marked pathological changes proximal and distal to the site of rupture in acute Achilles tendon ruptures. Knee Surg Sports Traumatol Arthrosc 2011; 19(4):680-687.

8. Del Buono A, Battery L, Denaro V, Maccauro G, Maffulli N. Tendinopathy and inflammation: some truths. Int J Immunopathol Pharmacol 2011; 24(1(suppl 2)):45-50.

9. Del Buono A, Papalia R, Denaro V, Maccauro G, Maffulli N. Platelet rich plasma and tendinopathy: state of the art. Int $\mathrm{J}$ Immunopathol Pharmacol 2011; 24(1(suppl 2)):79-83.

10. Maffulli N, Longo UG, Denaro V. Novel approaches for the management of tendinopathy. J Bone Joint Surg Am 2010; 92(15):2604-2613.

11. Danielson $\mathrm{P}$, Andersson $\mathrm{G}$, Alfredson $\mathrm{H}$, Forsgren $\mathrm{S}$. Marked sympathetic component in the perivascular innervation of the dorsal paratendinous tissue of the patellar tendon in arthroscopically treated tendinosis patients. Knee Surg Sports Traumatol Arthrosc 2008; 16(6):621-626.

12. Sharma $P$, Maffulli $N$. Tendon injury and tendinopathy: healing and repair. J Bone Joint Surg Am 2005; 87(1):187-202.

13. Via AG, De Cupis M, Spoliti M, Oliva F. Clinical and biological aspects of rotator cuff tears. Muscles Ligaments Tendons $\mathrm{J}$ 2013; 3(2):70-79.

14. Petersen W, Varoga D, Zantop T, Hassenpflug J, Mentlein $R$, Pufe T. Cyclic strain influences the expression of the vascular endothelial growth factor (VEGF) and the hypoxia inducible factor 1 alpha (HIF-1alpha) in tendon fibroblasts. J Orthop Res 2004; 22(4):847-853.

15. Birch HL, Wilson AM, Goodship AE. The effect of exerciseinduced localised hyperthermia on tendon cell survival. J Exp Biol 1997; 200(Pt 11):1703-1708.

16. Yuan J, Murrell GAC, Wei AQ, Wang MX. Apoptosis in rotator cuff tendonopathy. J Orthop Res 2002; 20(6):1372-1379.

17. Bedi A, Maak T, Walsh C, et al. Cytokines in rotator cuff degeneration and repair. J Shoulder Elbow Surg 2012; 21(2):218-227.

18. Murrell GA, Szabo C, Hannafin JA, et al. Modulation of tendon healing by nitric oxide. Inflamm Res 1997; 46(1):19-27.

19. Vangsness CT Jr, Ennis M, Taylor JG, Atkinson R. Neural anatomy of the glenohumeral ligaments, labrum, and subacromial bursa. Arthroscopy 1995; 11(2):180-184.

20. Soifer TB, Levy HJ, Soifer FM, Kleinbart F, Vigorita V, Bryk E. Neurohistology of the subacromial space. Arthroscopy 1996; 12(2):182-186.

21. Gotoh M, Hamada K, Yamakawa H, Inoue A, Fukuda H. Increased substance $P$ in subacromial bursa and shoulder pain in rotator cuff diseases. J Orthop Res 1998; 16(5):618-621.

22. Morrison DS, Bigliani LU. Roentgenographic analysis of acromial morphology and its relationship to rotator cuff tears. Orthop Trans 1987; $11: 439$.

23. Bright AS, Torpey B, Magid D, Codd T, McFarland EG. Reliability of radiographic evaluation for acromial morphology. Skeletal Radiol 1997; 26(12):718-721.

24. Hamid N, Omid R, Yamaguchi K, Steger-May K, Stobbs G, Keener JD. Relationship of radiographic acromial characteristics and rotator cuff disease: a prospective investigation of clinical, radiographic, and sonographic findings. J Shoulder Elbow Surg 2012; 21(10):1289-1298.

25. Jacobson SR, Speer KP, Moor JT, et al. Reliability of radiographic assessment of acromial morphology. J Shoulder Elbow Surg 1995; 4(6):449-453.

26. Shin SJ, Oh JH, Chung SW, Song MH. The efficacy of acromioplasty in the arthroscopic repair of small- to medium-sized rotator cuff tears without acromial spur: prospective comparative study. Arthroscopy 2012; 28(5):628-635.

27. Budoff JE, Nirschl RP, Guidi EJ. Debridement of partial-thickness tears of the rotator cuff without acromioplasty. Longterm follow-up and review of the literature. J Bone Joint Surg Am 1998; 80(5):733-748.

28. Codman EA. Rupture of the supraspinatus tendon. In: The Shoulder Rupture of the Supraspinatus Tendon and Other Lesions in or about the Subacromial Bursa. Boston; Thomas Todd 1934; 123-177.

29. Pollock RG, Flatow EL. The rotator cuff, part II. Full-thickness tears. Mini-open repair. Orthop Clin North Am 1997; 28(2):169-177.

30. Holt EM, Allibone RO. Anatomic variants of the coracoacromial ligament. J Shoulder Elbow Surg 1995; 4(5):370375.

31. McCallister WV, Parsons IM, Titelman RM, Matsen FA, III. Open rotator cuff repair without acromioplasty. J Bone Joint Surg Am 2005; 87(6):1278-1283.

32. Goldberg BA, Lippitt SB, Matsen FA, III. Improvement in comfort and function after cuff repair without acromioplasty. Clin Orthop Relat Res 2001; 390:142-150.

33. MacDonald P, McRae S, Leiter J, Mascarenhas R, Lapner P. Arthroscopic rotator cuff repair with and without acromioplasty in the treatment of full-thickness rotator cuff tears: a multicenter, randomized controlled trial. J Bone Joint Surg Am 2011; 93(21):1953-1960.

34. Chahal J, Mall N, MacDonald PB, et al. The role of subacromial decompression in patients undergoing arthroscopic repair of full-thickness tears of the rotator cuff: a systematic review and meta-analysis. Arthroscopy 2012; 28(5):720-727.

35. Harryman DT II, Mack LA, Wang KY, Jackins SE, Richardson ML, Matsen FA III. Repairs of the rotator cuff. Correlation of functional results with integrity of the cuff. J Bone Joint Surg Am 1991; 73(7):982-989.

36. Boileau P, Brassart N, Watkinson DJ, Carles M, Hatzidakis AM, Krishnan SG. Arthroscopic repair of full-thickness tears of the supraspinatus: does the tendon really heal? $\mathrm{J}$ Bone Joint Surg Am 2005; 87(6):1229-1240.

37. DeFranco MJ, Bershadsky B, Ciccone J, Yum JK, lannotti JP. Functional outcome of arthroscopic rotator cuff repairs: a correlation of anatomic and clinical results. J Shoulder Elbow Surg 2007; 16(6):759-765. 
38. Hyvonen P, Lohi S, Jalovaara P. Open acromioplasty does not prevent the progression of an impingement syndrome to a tear. Nine-year follow-up of 96 cases. J Bone Joint Surg Br 1998; 80(5):813-816.

39. Kartus J, Kartus C, Rostgard-Christensen L, Sernert N, Read J, Perko M. Long-term clinical and ultrasound evaluation after arthroscopic acromioplasty in patients with partial rotator cuff tears. Arthroscopy 2006; 22(1):44-49.

40. Papadonikolakis A, McKenna M, Warme W, Martin BI, Matsen FA, III. Published evidence relevant to the diagnosis of impingement syndrome of the shoulder. J Bone Joint Surg Am 2011; 93(19):1827-1832.

41. American Academy of Orthopaedic Surgeons. Optimizing the management of rotator cuff problems: guideline and evidence report. Available at http://www.aaos.org/research/guidelines/RCP_guideline.pdf. Accessed on July 10. 2012.

42. Ozaki J, Fujimoto S, Nakagawa Y, Masuhara K, Tamai S. Tears of the rotator cuff of the shoulder associated with pathological changes in the acromion. A study in cadavera. J Bone Joint Surg Am 1988; 70(8):1224-1230.
43. Mehta S, Gimbel JA, Soslowsky LJ. Etiologic and pathogenetic factors for rotator cuff tendinopathy. Clin Sports Med 2003; 22(4):791-812.

44. Braman JP, Zhao KD, Lawrence RL, Harrison AK, Ludewig PM. Shoulder impingement revisited: evolution of diagnostic understanding in orthopedic surgery and physical therapy. Med Biol Eng Comput 2013; Epub ahead of print, Apr 10 (DOI:10.1007/S11571-013-1074-1).

45. Ludewig PM, Reynolds JF. The association of scapular kinematics and glenohumeral joint pathologies. J Orthop Sports Phys Ther 2009; 39(2):90-104.

46. Kibler WB, Sciascia A. Current concepts: scapular dyskinesis. Br J Sports Med 2010; 44(5):300-305.

47. Ludewig PM, Cook TM. Alterations in shoulder kinematics and associated muscle activity in people with symptoms of shoulder impingement. Phys Ther 2000; 80(3):276-291.

48. Lewis JS, Valentine RE. Clinical measurement of the thoracic kyphosis. A study of the intra-rater reliability in subjects with and without shoulder pain. BMC Musculoskelet Disord 2010; 11(39):1-7. 